\title{
PROFESSORES COMO PESQUISADORES E A COLABORAÇÃO ENTRE PARES: PESQUISA, INFORMAÇÃO E CONHECIMENTO NO CONTEXTO ESCOLAR
}

TEACHERS AS RESEARCHERS AND COLLABORATION AMONG THEIRS: RESEARCH, INFORMATION AND KNOWLEDGE IN SCHOOL

\author{
MAESTROS COMO INVESTIGADORES Y COLABORACIÓN ENTRE \\ COMPAÑEROS: INVESTIGACIÓN, INFORMACIÓN Y CONOCIMIENTO \\ EN EL CONTEXTO ESCOLAR
}

\begin{abstract}
Cintia Kath Blank ${ }^{1}$
João Alberto da Silva ${ }^{2}$

RESUMO

Este trabalho se propôs a compreender, na perspectiva do letramento informacional, a atividade da pesquisa escolar desenvolvida pelos professores para sua atuação e atualização profissional. Para o desenvolvimento deste estudo participaram sete docentes dos anos iniciais de duas escolas de ensino fundamental da rede municipal de uma cidade do interior do Rio Grande do Sul, integrantes do Programa Observatório Nacional da Educação - CAPES. Em relação à abordagem metodológica, o delineamento se sustenta na Investigação-ação escolar com a utilização de técnicas de Grupo focal; Planejamento cooperativo e a observação, os quais foram posteriormente analisados com auxílio do aporte teórico-metodológico da Análise de Conteúdo. Os dados analisados apontam que são praticadas buscas e não propriamente pesquisas, já que o foco na prática está na localização de informações e não na construção de conhecimentos. Nas pesquisas desenvolvidas pelos professores, a atenção está na aplicabilidade das informações coletadas em suas turmas e, para isso, recorrem a colegas de profissão e blogs de outros professores. O compartilhamento de informações e a divulgação de dados das pesquisas aparecem frequentemente praticados pelos docentes e a principal dificuldade citada por eles é a problemática da cultura escolar com o trabalho de pesquisa. Assim, a pesquisa escolar, na perspectiva do letramento informacional, mostrou que, embora as intenções sejam condizentes com uma visão construtivista, na prática, este fato não se concretiza.
\end{abstract}

PALAVRAS-CHAVE: Professor pesquisador. Formação de professores. Letramento informacional. Ensino fundamental - Anos iniciais.

\section{ABSTRACT}

This study aims to understand in the perspective of information literacy the school research activity developed by teachers for their performance and professional improvement. In development of this study participated seven teachers in the early years of two elementary school in the municipal town in

\footnotetext{
${ }^{1}$ Mestrado em Educação - Universidade Federal do Rio Grande (FURG) - Rio Grande, RS - Brasil. Graduação em Biblioteconomia - Universidade Federal do Rio Grande (FURG) - Rio Grande, RS - Brasil. Bibliotecária da Prefeitura Municipal do Rio Grande, RS - Brasil. E-mail: cintiadabiblio@gmail.com 2 Pós-doutorado em Educação Matemática - Universidade Federal de Pernambuco (UFPE) - Recife, PE Brasil. Doutorado em Educação - Universidade Federal do Rio Grande do Sul (UFRGS) - Porto Alegre, RS Brasil. Professor Adjunto - Universidade Federal do Rio Grande (FURG) - Rio Grande, RS - Brasil. E-mail: oaopiaget@gmail.com
}

Submetido em: 22/12/2015 - Aceito em: 11/07/2016

(C) ETD-Educação Temática Digital Campinas, SP v.19 n.3 $\quad$ p. 786-804 jul./set. 2017 
interior of Rio Grande do Sul, members of the a Gouverment Program for teachers. Regarding the methodological approach, the design is based on academic research-action with the use of techniques Focus Group; Cooperative planning and observation, which were subsequently analyzed using the theoretical and methodological support of Content Analysis. The data analyzed show that searches are practiced and not properly research, since the focus in practice is finding information and not in the construction of knowledge. In research carried out by teachers, the attention is on the applicability of the information collected in their classes and, therefore, turn to peers and blogs of other teachers. Information sharing and dissemination of research data often appear committed by teachers and the main difficulty cited by them is the issue of school culture with the research. Thus, the scholarly research from the information literacy perspective showed that although the intentions are consistent with a constructivist view, in practice, this fact is not realized.

KEYWORDS: Teacher researcher. Teacher training. Information literacy. Elementary school - early years

\section{RESUMEN}

Este estudio tiene como objetivo comprender, por la perspectiva de la alfabetización informacional, la actividad de investigación de la escuela desarrollada por los maestros para su desempeño y desarrollo profesional. Así, en el desarrollo de este estudio participaron siete maestros de los años iniciales de dos escuelas primarias, situadas en una localidad de una zona rural de Río Grande do Sul y miembros del Programa de Educación del Observatorio Nacional - CAPES. En cuanto al enfoque metodológico, el diseño se basa en la investigación-acción con el uso de técnicas de Enfoque de grupo; la planificación y la observación cooperativa, que fueron analizados a posteriori y mediante técnicas de análisis de contenido. Los datos analizados muestran que las búsquedas que se practican tienen un carácter más de búsqueda que investigación, es decir, el objetivo es encontrar información y no la construcción de conocimiento.. En la investigación llevada a cabo por los profesores, la atención está centrada en la aplicabilidad de la información recogida tanto en sus clases, como de sus compañeros y blogs de otros profesores. El intercambio de información y la difusión de datos de la investigación a menudo aparecen realizados por maestros y la principal dificultad citada por ellos es el tema de la cultura de la escuela hacia la investigación. Así, la investigación académica, desde la perspectiva de la alfabetización informacional, mostró que a pesar de las intenciones son consistentes con una visión constructivista, en la práctica, este hecho no se produce de la forma correcta.

PALABRAS CLAVE: Profesor de Investigación. Formación del profesorado. Alfabetización informacional. Escuela primaria - primeros años.

\section{INTRODUÇÃO}

Refletir sobre a educação considerando os recursos informacionais e midiáticos da atualidade é ação que pode estar pautada em uma consciência de mutação constante destes fatores integrantes (LÉVY, 2003). Diante de um cenário instável, tornou-se preocupação das instituições de ensino educar as próximas gerações para esta sociedade baseada na emergência da circulação de informações. Neste contexto, capacidades como pesquisa, avaliação, ética, produção e disseminação informacional podem ser trabalhadas a fim de tornarem os profissionais ligados à educação capacitados a interagirem neste meio e ensinar estas habilidades aos seus discentes.

Assim posto, este artigo objetiva apresentar os resultados de uma pesquisa realizada com docentes participantes do programa Observatório Nacional da Educação
(C) ETD-Educação Temática Digital
Campinas, SP
v.19 n.3
p. $786-804$
jul./set. 2017 
atuantes nos anos iniciais do Ensino Fundamental de duas escolas públicas municipais de uma cidade do interior do Rio Grande do Sul. Partindo de uma perspectiva construtivista de construção do conhecimento, aliada com a concepção do letramento informacional, buscou-se compreender quais são os conceitos e procedimentos dos docentes dos anos iniciais do ensino fundamental acerca da atividade de pesquisa de cunho teórico e conceitual desenvolvida por eles mesmos.

Além disso, o foco desta investigação recai sobre os anos iniciais do ensino fundamental por alinhar-se com a tendência que destaca a importância do trabalho com informação, pesquisa e construção do conhecimento desde os primeiros anos escolares (GASQUE, 2012) e pelo fato de que "não há ensino sem pesquisa e pesquisa sem ensino" (FREIRE, 2007, p. 29). Considerou-se primordial, então, ouvir os docentes sobre suas concepções e experiências a respeito da pesquisa escolar neste nível de ensino, pois entende-se que se o professor "é passivo intelectualmente, não conseguirá ser livre moralmente" (PIAGET, 2002, p. 61).

\section{O PROFESSOR NO SENTIDO ESTRITO E NO SENTIDO AMPLO EM UM CONTEXTO INFORMACIONAL}

Falar da constituição do professor como pesquisador impõe, antes de tudo, a reflexão em relação a diferentes concepções de pesquisa e dos professores que as executam. Dessa forma, para se compreender a atividade da pesquisa e da construção do conhecimento no âmbito escolar, cabe trazer aqui a concepção de professor lato sensu (sentido amplo) e de professor stricto sensu (sentido estrito) permeada pela questão informacional.

Distinguindo assim que tanto o professor quanto a pesquisa no sentido estrito é "a que é feita por docentes universitários, como atividade universitária específica, ao lado do ensino e da extensão, mediante projetos de pesquisa, realizados em laboratórios apropriados ou como pesquisa de campo" (BECKER, 2012a, p. 11), caracterizando-se por ter objetivos de estudo bem específicos e em geral requer longo tempo de dedicação em uma mesma temática. Já o docente no sentido amplo constitui-se como aquele

professor que não reduziu sua função às realizações de uma máquina de ensinar ou aos procedimentos burocratizados de um "ensinador", constrói e, sobretudo, reconstrói conhecimentos. É o que faz um pesquisador, pois um conhecimento nunca inicia do zero e nunca é levado a termo de forma definitiva. Ele assim procede não para ser pesquisador, mas para ser plenamente professor. Nesse sentido, pesquisar faz parte da função docente. Faz parte da nova concepção de professor (BECKER, 2012a, p. 13).

(C) ETD-Educação Temática Digital $\quad$ Campinas, SP $\quad$ v.19 $\quad$ n.3 $\quad$ p.786-804 jul./set. 2017 
O professor lato sensu caracteriza o perfil de profissional que constrói e reconstrói seus conhecimentos e de seus aprendizes, utilizando sua sensibilidade e profissionalismo para ministrar aulas sem ater-se demasiadamente em burocracias, além de considerar os conhecimentos existentes como base para o desenvolvimento de novos e percebe as atuais concepções de ser professor em uma sociedade do conhecimento. No mesmo sentido temos as palavras de Piaget (2002), para quem uma aprendizagem no sentido estrito também pode ser concebida como aquela que se restringe à transmissão e aquisição de conteúdos, mas a aprendizagem no sentido amplo será a que permitirá a construção de conhecimentos a partir das informações adquiridas na aprendizagem stricto sensu.

De acordo com a configuração de ensino e de aprendizagem que se vislumbra neste trabalho, o papel do professor desloca-se substancialmente de uma concepção pedagógica diretiva e de uma epistemologia empirista para um modelo pedagógico relacional e uma concepção epistemológica construtivista. Segundo Becker (2012), no empirismo o professor é o centro do processo e os estudantes meros receptores. De acordo com este modelo epistemológico, o docente crê no mito da transmissão do conhecimento, ou seja, o discente só aprende o que o professor ensina, não existindo conhecimento precedente ao do transmitido pelo professor. Como possibilidade de superação deste modelo, os educadores devem se perguntar que tipos de cidadão pretendem formar: passivos e obedientes ou críticos, problematizadores e reflexivos?

Assim, a concepção epistemológica e pedagógica defendida baseia-se no construtivismo, podendo ser conceituado como uma teoria, uma ideia, uma forma de ver o mundo na qual, fugindo de concepções empiristas e aprioristas, não concebe o desenvolvimento humano como algo terminado ou determinado, mas entende que tudo o que nos permeia pode ser construído e reconstruído por meio de nossa ação (BECKER, 1992; 2012). Assim, se o professor conceber seu educando de um ponto de vista construtivista, não o tomará como tabula rasa, tampouco como um "semideus" que já traz em si todas as respostas (BECKER, 1992). O docente que perceber seu discente como um sujeito culturalmente ativo poderá ver que ele se desenvolve em uma dimensão assimiladora (produzindo transformações no mundo objetivo) e acomodadora (produzindo transformações em si mesmo).

A concretização de um ideal de construção de conhecimento a partir de atividades de pesquisa, a capacitação e a conscientização dos docentes da Educação Básica para além de profissionais transmissores de informações (no sentido stricto sensu) torna-se fundamental caso seja almejado algum nível de transformação educacional. Corroborando com Piaget (2002, p. 25-26)

(C) ETD-Educação Temática Digital Campinas, SP $\quad$ v.19 $\quad$ n.3 $\quad$ p.786-804 jul./set. 2017 
A preparação dos professores [...] constitui realmente a questão primordial de todas as reformas pedagógicas em perspectiva, pois, enquanto não for a mesma resolvida de forma satisfatória, será totalmente inútil organizar belos programas ou construir belas teorias a respeito do que deveria ser realizado.

Ademais, segundo Dickel (1998, p. 53) “o professor é um observador participante potencial nas aulas e escolas, do ponto de vista da observação naturalista; e de qualquer ponto de vista, o professor é rodeado por oportunidades de investigar". Contudo, uma formação para o trabalho com informação e conhecimento além de parcerias dentro do âmbito escolar são condições sine qua non para o docente assumir seu papel de liderança intelectual e investigativa em sua ação pedagógica cotidiana.

\title{
LETRAMENTO INFORMACIONAL E CONSTRUÇÃO DO CONHECIMENTO ESCOLAR POR MEIO DA PESQUISA
}

Vive-se uma era de substanciais transformações em nossas rotinas, onde as atividades humanas estão sendo transformadas, de alguma forma, pelo intensivo uso das TICs (tecnologias da informação e comunicação). Esta nova conjuntura social caracteriza-se pela intensa circulação de informações, possibilidades de comunicação nunca antes vistas e ampliação dos espaços de aprendizagem (LIBÂNEO; OLIVEIRA; TOSCHI, 2009). Neste sentido, torna-se "equivocado considerar que o que é necessário aprender seja planejado ou definido com larga antecedência sem que haja as devidas atualizações sempre emergentes devido ao intenso fluxo informacional de nossa era" (LÉVY, 2003, p. 158) o que move todos os indivíduos a uma busca contínua por novas aprendizagens.

A resolução de problemas no cotidiano muitas vezes ocorre de modo intuitivo, mas dada esta crescente complexidade de nossa sociedade, o trabalho com informação tornou-se indispensável se pensarmos em uma escola que se estabelece a partir da formação de indivíduos para a vida. Neste contexto, emerge a urgência da temática do letramento informacional conforme apontam Gasque e Tescarolo (2010, p. 44):

\begin{abstract}
As pessoas, na maioria das vezes, não tem oportunidade de sistematizar o conhecimento necessário para buscar e usar informação, agindo quase sempre de forma intuitiva. No entanto, para a resolução de problemas mais complexos, a literatura especializada menciona que a eficácia do processo de aprendizagem depende, em grande parte, da qualidade da informação, considerando-se os critérios de confiabilidade, atualidade e autoridade, bem como da análise das diversas concepções na área de estudo, o que pressupõe o desenvolvimento do letramento informacional.
\end{abstract}

(C) ETD-Educação Temática Digital $\quad$ Campinas, SP $\quad$ v.19 $\quad$ n.3 $\quad$ p.786-804 jul./set. 2017 [790] 
Gasque (2010, p.86) considera que "o letramento informacional relaciona-se à capacidade de buscar e usar a informação eficazmente", envolvendo a pesquisa, a produção de textos próprios, aplicação da informação em atividades cotidianas entre outras, exigindo um maior engajamento do sujeito no universo informacional. Assim, cabe situar a adoção neste trabalho da definição de letramento informacional proposta por Gasque (2012, p. 28), que demarca letramento informacional como sendo "um processo de desenvolvimento de competências para localizar, selecionar, acessar, organizar, usar informação e gerar conhecimento, visando à tomada de decisão e à resolução de problemas".

Considerando o professor como pesquisador, percebe-se este como uma das figuras fundamentais de todo o processo, e a prática da pesquisa em seu fazer docente como possibilidade de qualificação profissional e pessoal, conforme aponta Dickel (1998, p. 33-34):

\begin{abstract}
A pesquisa talvez seja, nesse contexto de escola pública, a possibilidade de $o$ professor tomar a si o direito pela direção de seu trabalho e, comprometendo-se com a busca de uma sociedade justa, torná-lo capaz de provocar em seus alunos a capacidade de inventar um mundo alternativo. Para tanto, a crítica ao trabalho pedagógico, à escola e à realidade, associada a um empenho em buscar nos conhecimentos produzidos pelos professores e pelas crianças o que há de novo e potencialmente capaz de contribuir nessa luta, são fundamentais.
\end{abstract}

Torna-se necessário, então, que seja refletida a ideia de que embora o meio exerça influência em nossa constituição como sujeitos epistêmicos e psicológicos, este não nos determina. Por isso, assumir um posicionamento de educador comprometido com a construção do conhecimento implica considerar que "pesquisar é cada um participar ativamente da construção do seu conhecimento e da construção do conhecimento daqueles com os quais convive no mesmo processo educativo" (RAMOS, 2004, p. 37), promovendo uma transformação de si para os outros, partindo do pessoal e transbordando para o coletivo. Este é o cerne do professor que promove o aprendizado pela pesquisa: "pesquisar as ações exercidas em sala de aula, do ponto de vista das condutas discentes e, também, de suas próprias condutas" (KEBACH, 2012, p. 53).

Atentamos também para o fato de que no trabalho com pesquisa e informação o professor tem a possibilidade de superar a aula que se "sustenta" a partir de atividades de cópias e reproduções, construindo um novo caminho, no qual a pesquisa possibilita o envolvimento de estudantes e professores em um processo participativo e comunicativo de construção e reconstrução de conhecimentos (FRISON, 2004, p.150). Assim, destaca-se que tanto educando como educador que tenha em seu
(C) ETD-Educação Temática Digital
Campinas, SP
v.19
n.3
p. $786-804$
jul./set. 2017 
cotidiano atividades envolvendo pesquisa estará desenvolvendo conteúdos conceituais (fatos, situações, conceitos relativos à temática de estudo), procedimentais (procedimentos, habilidades, destrezas técnicas para a execução da tarefa proposta) e atitudinais (postura, valores, comportamentos referentes ao acesso, uso, compreensão e comunicação da informação) (GASQUE, 2012), além de uma formação humana que capacite o indivíduo a intervir na realidade com qualidade formal e política (MORAES, 2004) e possibilite liberdade do pensamento (SILVA, 2012).

Evidencia-se, dessa forma, o caráter transformador da atividade da pesquisa escolar desde que superadas antigas concepções pedagógicas reducionistas, no qual tanto o docente qualifica seu trabalho exercendo liderança intelectual no meio escolar, assim como possibilita aos estudantes o desenvolvimento pleno enquanto sujeitos com singularidades respeitadas e como cidadãos partícipes de uma comunidade. Dessa maneira, destaca-se a colocação de Silva $(2012$, p. 73$)$ que traz de maneira enfática a possibilidade da construção do novo por meio de uma educação pela pesquisa, ideal mobilizador deste:

$\mathrm{Na}$ atividade da pesquisa, entendida no âmbito do construtivismo, o professor e o aluno ganham novo status. O professor-pesquisador se complementa na dinâmica do aluno-pesquisador, produzindo como síntese a liberdade do pensamento e uma nova dimensão do exercício da docência e da discência. Nesse sentido, a pesquisa deve privilegiar a ação e a experimentação, deixando o pensamento livre para enfrentar obstáculos, para inventar, deparar-se com os erros e solucioná-los, pois é justamente nesse processo de superação que se efetiva a construção do novo.

Finalmente, destaca-se o fato de que a resposta para a problemática da pesquisa escolar reside em uma harmoniosa união de fatores, tais como os já levantados, mas que podem ser expandidos ou redirecionados de acordo com o contexto educacional sobre o qual os olhares reflexivos estiverem sendo lançados. Contudo, se acreditamos em uma educação verdadeiramente formadora de cidadãos, libertária e significativa face ao contexto no qual vivemos, torna-se indispensável a transposição de práticas pedagógicas e concepções epistemológicas cerceadoras para ideologias e práticas que tornem os indivíduos intelectualmente autônomos, estejam estes na posição de docentes ou discentes.

\section{METODOLOGIA}

Partindo-se de um delineamento metodológico inspirado na Investigaçãoação escolar (COUTINHO, 2009), a produção dos dados que serviram de base para a análise neste estudo ocorreu em três momentos distintos, mas complementares. 0 primeiro momento consistiu na realização de dois grupos focais com os docentes das (C) ETD-Educação Temática Digital $\quad$ Campinas, SP $\quad$ v.19 $\quad$ n.3 $\quad$ p. 786-804 $\quad$ jul./set. 2017 [792] 
escolas integrantes do programa a fim de que fosse possibilitada a troca de experiências bem como reflexões iniciais acerca dos temas pesquisa escolar, letramento informacional, busca e uso de informações pelo professor. Essas professoras participantes do citado programa atuaram em diferentes projetos de investigação sustentados pela investigação-ação. Todas possuem nível superior e estão em exercício nos anos iniciais há mais de 8 anos.

Iniciando pela temática "pesquisa escolar", foi indagado aos professores sobre o que compreendem com relação a este tema, assim como foi inquirido acerca de experiências que vislumbraram trazer à tona sobre impressões dos tempos em que eram estudantes e realizavam pesquisas escolares, relacionando estas experiências com a atualidade ao proporem esta atividade aos seus educandos (ou, quando fosse o caso, que fossem apresentadas justificativas para a não utilização deste método). Em continuidade, indagou-se como ocorrem suas pesquisas/buscas por informações no âmbito profissional. Cabe acentuar, neste contexto, que os registros do grupo focal foram realizados por meio de filmagem e áudio e foram posteriormente interpretados pela técnica de Análise de Conteúdo (BARDIN, 2002).

Devido ao fato de entendermos o docente como um colaborador, o segundo momento da investigação deu-se através do Planejamento Cooperativo (SILVA; MARINHO; SILVA, 2015) entre pesquisadora e professoras. Para o desenvolvimento deste momento da pesquisa, idealizou-se que as professoras participantes articulassem juntamente planos de aula envolvendo a atividade de pesquisa escolar e recursos informacionais. O objetivo deste momento da pesquisa foi compreender como as professoras planejam suas aulas envolvendo o trabalho com informação e a pesquisa escolar, quais os recursos que mobilizariam e quais as estratégias metodológicas seriam empregadas.

A observação nas escolas constitui o terceiro passo do percurso metodológico e objetivou acompanhar na prática a implantação do discutido e do idealizado nos encontros anteriores, sendo este momento de coleta de dados registrado em diário de campo e gravação. Desta maneira, foi observado o desenvolvimento das atividades propostas no momento do planejamento cooperativo a fim de subsidiar a posterior reflexão sobre o resultado da ação. Por fim, deu-se um momento de reflexão das participantes no qual foi mediada a análise das professoras sobre o caminho percorrido a fim de serem identificados pontos positivos, aspectos que podem ser melhorados e sugestões de desdobramentos da atividade implementada. Todas as atividades deste momento foram registradas em diário de campo.

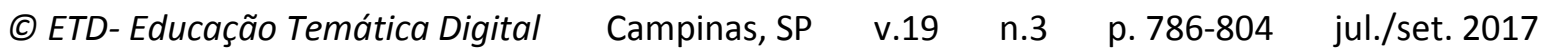
[793] 


\section{ANÁLISE DOS DADOS}

No contexto das explanações-respostas que partem das docentes, quando chamadas a refletir sobre o conceito de pesquisa, diversas ideias são expostas, e nelas temas como autonomia, atualização e conhecimento surgem em várias passagens:

Eu pesquiso muito porque a gente tem que estar sempre bem informado pra poder passar pra eles, porque eles estão sempre perguntando (Grupo Focal - Professora $\mathrm{P} 1$ - 4음.

Para mim, a pesquisa consiste no ato de conhecer sobre o desconhecido (Avaliação da atividade - Professora P1 - 4으ano).

Pesquisar não é cópia. É tirar do texto o que interessa para o trabalho (Observação - Professora P1 - 40 ano).

Então eu acho que a pesquisa pra nós educadores, está na maneira de como trabalhar o conhecimento que muitas vezes a criança já tem, em algumas coisas sabe até mais que a gente (Grupo Focal - Professora P3 - 4o ano).

Eu acho que pesquisar é buscar conhecimentos de alguma coisa que me causa curiosidade ou que eu não tenho domínio. Seja por uma necessidade pessoal ou até por uma necessidade da função, de ser professora (Grupo Focal - Professora P4 -2 o ano).

A gente sempre pesquisa pra tirar dúvidas, mas também acontece de virem novas dúvidas, um conhecimento sempre traz outro (Grupo Focal - Professora P6 - 40 ano).

De maneira unânime, percebe-se que a pesquisa possui um aspecto positivo por parte das docentes, além de mostrar-se como um modo de tirar dúvidas e sanar curiosidades. Também é percebida como um momento que possibilita a formação de si, o que demonstra a intenção de um movimento contínuo de construção de conhecimentos. Quando a motivação para o desenvolvimento de uma pesquisa mobiliza aspectos pessoais de interesse dos participantes, envolvendo curiosidades e dúvidas vinculadas aos sujeitos como indicadas pelas Professoras P1 e P4, tanto o desenvolvimento da atividade se mostrará mais proveitoso quanto se mostrará como um estímulo para a recorrência do processo, como podemos inferir a partir do relato da Professora P6.

Estes relatos também trazem a ideia de pesquisa tanto como prática de formação e atualização do professor quanto método de ensino a fim de diversificar as aulas. No que diz respeito à pesquisa como formação de si, surgem as instâncias de atualização, de curiosidade e de autonomia, demonstrando o caráter formativo que a pesquisa tem a partir das vivências dos sujeitos inseridos na pesquisa. Já ao pensarmos (C) ETD-Educação Temática Digital 
na pesquisa como método de ensino, as educadoras demonstram neste momento que aspectos como informação, conhecimento, contextualização e aprendizagem parecem estar mais ligados ao trabalho para e com os aprendizes. Além do mais, a ideia de compartilhamento de informações parece bem presente como um movimento natural do trabalho com pesquisa e informação, conforme indicam as falas das Professoras P1 e P3. Deste modo, a comunicação de descobertas, aprendizados e novidades é um momento crucial do movimento da pesquisa, no qual, com a troca de saberes entre os envolvidos, a experiência do conhecimento torna-se viva, podendo ser corroborada, refutada, revista, ampliada.

A pesquisa também aparece nas falas como algo próximo das atividades docentes. As professoras P1 e P4 sinalizam esta percepção ao considerar que o trabalho com educação e com a quantidade e diversidade de necessidades dos discentes as movem no sentido de terem a necessidade de constante atualização, utilizando-se assim da pesquisa como forma autônoma de solução de suas necessidades informacionais.

A partir do exposto, cabe então refletirmos: como, onde e com quem estas dúvidas e curiosidades seriam sanadas a fim de trazer autonomia e atualização às docentes por meio da pesquisa, da busca de informações e da construção de conhecimentos? Para compreendermos o comportamento informacional das professoras, então, nos valemos de alguns recortes de suas falas:

Eu e a Professora P3 trabalhamos juntas no 4을 ano, então tem muita troca, e ela gosta muito de trabalhar produções textuais, então eu pesquisei um monte de coisas novas pra dar pra ela, porque ela me passa tanta coisa que eu precisava também dar pra ela alguma coisa. E eu saí em busca também pra mostrar pra ela que eu também estava inserida nesse trabalho. E agora eu também estou aprendendo a trabalhar produção textual com ela. E não precisa ter tempo pra marcar e combinar uma atividade, até o corredor serve (Grupo Focal - Professora

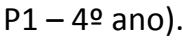

Hoje, com o avanço tecnológico, a pesquisa se dá mais na Internet (páginas específicas, artigos, blogs,...) mas busca-se também na literatura [impressa], troca de experiências com nossos pares e demais colegas (Avaliação da atividade Professora P3 - 4ㅇao.

Hoje eu utilizo muito a internet, livros e coleções nem uso mais, tenho um monte guardada, porque elas são muito tradicionais (Grupo Focal - Professora P5 - 3으 ano).

E nos blogs a gente já divide experiências, porque já colocam ali como foi na turma delas, e nos comentários vem outros professores que contam como fizeram e dão sugestão de como fazer diferente também. E no Facebook também tem grupos assim, muito bons (Grupo Focal - Professora P6 - 4ㅇano).

(C) ETD-Educação Temática Digital $\quad$ Campinas, SP $\quad$ v.19 $\quad$ n.3 $\quad$ p.786-804 jul./set. 2017 [795] 
Nestes relatos, percebe-se de maneira majoritária a presença da internet e de colegas de profissão como frequentes canais de informação ${ }^{3}$. Neste sentido, podemos perceber que os dados encontrados estão condizentes com a literatura, já que Gasque (2012) apontou que os canais mais utilizados pelas professoras eram os arquivos pessoais e os arquivos de colegas, mas que a utilização de computadores e da internet pareceria emergir substancialmente. No entanto, quando as professoras relatam preferirem canais que possibilitem troca de informações entre pares (como no caso dos blogs e grupos no Facebook como citam as professoras P3, P5 e P6), não se percebe clareza ou especificidade na indicação de fontes de informação ${ }^{4}$ que utilizam, podendo assim considerar que os próprios relatos dos pares são importantes fontes de informação para as docentes, fato também mencionado pela Professora P1. Outro dado também apontado pela Professora P5 é a constatação de que com a crescente velocidade de troca de informações, as tradicionais "coleções pedagógicas", utilizadas por muito tempo como manuais pelos educadores em geral, na atual conjetura de circulação de informações, já se mostram ultrapassadas sendo, de certa forma, substituídas por atividades compartilhadas via Web, mais dinâmicas e interativas.

A opção pelo relato de outros docentes faz com que este se constitua como fonte de informação mais utilizada, seja oriunda de colegas da própria escola ou advinda do compartilhamento de experiências por meio de outras redes de comunicação. Isto nos parece indicar para três vieses de inferência da situação: a falta de conhecimento para a exploração de outras fontes de informação mais confiáveis e com respaldo científico, além de meramente prático; a falta de tempo dentre seus afazeres pedagógicos para uma investigação mais aprofundada; e também, escassos recursos informacionais e tecnológicos que permitissem às docentes outras opções de canais e fontes de informação especializadas.

Embora o compartilhamento de experiências e materiais entre as educadoras fortaleça seus laços de colaboração como profissionais, torna-se importante observar que a própria ausência de referência a fontes de informação formais (livros, revistas, páginas institucionais da $(\mathrm{eb})$ e a constante indicação de conversas entre pares e relatos de outros professores (fontes informais) nos apontam para um possível embasamento conceitual fragilizado, focando a avaliação dos materiais na aplicabilidade em atividades de dinamização das aulas. Neste sentido, entende-se que

\footnotetext{
${ }^{3}$ Concebemos para a construção deste trabalho canais de informação como os meios ou vias utilizadas para se chegar a determinado recurso informacional como, por exemplo: internet, bibliotecas, arquivos pessoais.

${ }^{4}$ Fontes de informação são os suportes que abrigam as informações como, por exemplo: livros, revistas, CD's, jornais.
}
(C) ETD-Educação Temática Digital
Campinas, SP
v.19
n.3
p. $786-804$
jul./set. 2017 
existe uma confusão de significados entre as palavras "busca" que em suma designa a localização de materiais, com a ideia de "pesquisa" que possui todo um viés de construção de conhecimentos (que pressupõe a integração de informações novas às estruturas já existentes) e, deste modo, podemos apreender que, geralmente, são realizadas buscas, e não pesquisas.

Pensarmos na diferença entre a busca - que resultará em um processo de localização e consequente cópia - e a pesquisa - que objetiva um trabalho intelectual nos remete a um modelo pedagógico em que se concebe a cópia, a transmissão e o modelo padronizado como condições de aprendizagem ideais dos conteúdos escolares. Segundo Becker (2012), este modelo pedagógico é chamado de diretivo, e neste contexto, o professor agiria assim por acreditar que o conhecimento pode ser transmitido para os estudantes e que ensino e aprendizagem não são complementares, pregando assim um modelo baseado no fixismo, na reprodução e na repetição. Este modelo pedagógico, amplamente presente nas escolas em suas metodologias de ensino, deixa suas marcas e forma as bases para a aplicação em outros contextos, como no exposto nesta análise, nas pesquisas realizadas pelas docentes.

Ao desenvolver a pesquisa em suas atividades docentes como uma estrita busca, fica implícita a ideia de que a localização de materiais se sobrepõe em relevância e pertinência ao ideal de intelectualidade de uma pesquisa em um sentido amplo. Torna-se particularmente importante o fato de que, ao se desenvolver o ideal de pesquisa, este somente será possível com um trabalho que vise à construção de conhecimentos, que permita a reflexão, a criticidade e a tomada de consciência para os envolvidos. Contudo, ao efetuar uma mera localização de informações, podemos caracterizar esta como uma atividade de busca, na qual apenas conteúdos do tipo informações são mobilizados, sem que se ultrapasse uma camada superficial de entendimento do conteúdo e do processo em si.

Percebeu-se também que, embora a utilização de blogs e da internet seja relatada massivamente, as docentes também indicam já terem tido inconvenientes no uso destes canais de informação, como o plágio e o erro:

Uma coisa que eu observo é como tem gente que copia, copia, copia os blogs! Então eu hoje tenho uma seleção de 3 ou 4 blogs que eu sigo, e alguns há vários anos, e tem vezes que eu pesquiso alguma coisa no Google e aparece um monte de textos que copia um do outro, então tem que ter esse olhar do respeito com o trabalho do outro (Grupo Focal - Professora P3 - 40 ano).

(C) ETD-Educação Temática Digital $\quad$ Campinas, SP $\quad$ v.19 $\quad$ n.3 $\quad$ p.786-804 jul./set. 2017 
E também já encontrei coisas erradas, de encontrar exercícios na internet e me perguntar "será que eu aprendi errado?", e depois eu procurar alguém pra tirar a dúvida e via que realmente não estava certo (Grupo Focal - Professora P3 - 4은 ano).

Dar-se conta de informações erradas, plágios e inconsistências, sem dúvida demonstra atenção na avaliação das informações recuperadas. Este tipo de comportamento evidencia condutas de um letramento informacional, e ao que as docentes relataram no excerto acima, pode então fazer-nos inferir que as professoras participantes utilizam critérios de seleção e avaliação de conteúdos, de uma forma não totalmente sistemática e criteriosa como seria o ideal, mas apontam habilidades na avaliação de informações:

A busca de informações requer conhecer e avaliar diversas fontes de informações e suas características, ter domínio das tecnologias necessárias para buscar informação, ter critérios claros para avaliar as informações, dentre outras habilidades (GASQUE, 2012, p. 120).

Podemos entender, por meio das falas, um interesse pela busca de novas informações e de atualizações. Desta forma, características como pró-atividade e iniciativa são observadas nos seguintes momentos, em que as docentes se utilizam da pesquisa e de fontes de informação para melhorar sua prática:

Quando eu comecei em 93, ano que eu passei no concurso, eu fui dar aula no 1ㅇ ano, e eu não sabia alfabetizar, e peguei uma turma de 36 alunos pra alfabetizar, pra mim foi horrível, eu chegava em casa chorando e pensando "eu não vou conseguir alfabetizar essas crianças". Porque eu só conhecia o método tradicional. Aí eu fui estudando, pesquisando pra ver o que era melhor pra alfabetizar aquelas crianças. Foi tão bom que eu fiquei 10 anos alfabetizando. Pra ti ver como eu gostei dessa experiência (Grupo Focal - Professora P1 - 4o ano).

Eu gosto muito de no final da aula junto com eles lançar perguntas para a próxima aula. E eles já trazem coisas, e eu quero muito criar esse hábito com eles, não só pelo projeto, mas também criar esse hábito como uma postura pra nós professores, de sempre se perguntar coisas e trazer coisas novas (Planejamento cooperativo - Professora P3 - 40 ano).

Neste mesmo viés, algo que se mostrou muito marcante em diversas falas foi a participação no Programa Observatório da Educação como sendo um marco em suas ações docentes e importante oportunidade de formação continuada:

Mas eu tive bastante dificuldade de sair daquela coisa tradicional pra entrar no mundo da pesquisa como a gente pensa hoje. Eu fui mudar com esses professores aí do projeto (Grupo Focal - Professora P1 - 4ㅇano).

(C) ETD-Educação Temática Digital $\quad$ Campinas, SP $\quad$ v.19 $\quad$ n.3 $\quad$ p.786-804 $\quad$ jul./set. 2017 [798] 
Agora esse ano ficou tudo mais direcionado pra ciências por causa do projeto (Planejamento cooperativo - Professora P4 - 2ㅇano).

Quando eu entrei no projeto e me foi falado sobre os desafios matemáticos, antes de trabalhar aqui no projeto, eu achava outra coisa dos desafios matemáticos [...] E eu trabalho muito alfabetização, porque tenho muitos alunos não alfabetizados, então eu não trabalho tabuada, multiplicação, divisão, só os conceitos mesmo. $\mathrm{E}$ trabalhava da forma errada, até eu começar a frequentar o projeto. Aí depois disso, eu comecei a procurar blogs sobre desafios matemáticos e encontrei coisas bem relacionadas com o que aprendi aqui (Grupo Focal - Professora P5 - 3음o).

A maneira pela qual as docentes se referem ao Programa Observatório da Educação evidencia o valor da formação continuada. Conceber este tipo de aperfeiçoamento para além de um discurso por horas banalizado, como uma oportunidade de rever suas práticas e concepções, permite ao educador não somente contribuir com a aprendizagem dos estudantes, mas igualmente, qualificar e empoderar-se como profissional da educação diante dos vastos desafios cotidianos implicados na sua prática. Evidentemente, aos professores são atribuídas uma série de atividades as quais devem cumprir durante as horas de sua jornada de trabalho e, concomitantemente, diversas exigências surgem a eles na mesma velocidade em que uma sociedade da informação é capaz de produzir.

Assim, o resultado é uma soma de conteúdos, tecnologias e informações a serem revistos incessantemente pelos professores, ainda que sua formação inicial e sua própria forma de pensar sobre a prática não o tenham sensibilizado para esta realidade. Este fato é corroborado por Gasque (2012, p. 113) ao destacar que "muito frequentemente se exige que o docente seja didaticamente criativo, enquanto sua formação básica e continuada em serviço é pouco inovadora, às vezes mesmo anacrônica", mas enfatiza que "os professores precisam estar engajados em um processo de formação continuada para estarem aptos a auxiliar os aprendizes a lidar com a quantidade de informações novas".

A atuação do professor como pesquisador de sua prática integra outros aspectos que podem influenciar sua concretização de maneira satisfatória. Para Gasque e Tescarolo (2010), o trabalho com pesquisa, informação e conhecimento nas escolas possui diversas dificuldades para a sua realização e, dentre elas, é citada a cultura pedagógica presente nas escolas. Dificuldades como esta foram indicadas nos relatos das professoras:

A gente ainda tem colegas, equipe diretiva fortíssima e pais que pensam que caderno cheio é sinônimo de aprendizagem e não pensam na apropriação do conhecimento desse aluno. E nós temos a cabeça mais aberta, fizemos uma universidade e estamos no projeto, estamos nos fundamentando, temos a prática,

$\begin{array}{llllll}\text { (C) ETD-Educação Temática Digital } & \text { Campinas, SP } & \text { v.19 } & \text { n.3 } & \text { p.786-804 } & \text { jul./set. } 2017\end{array}$ [799] 
a vontade que é fundamental de querer ver as coisas, que nós somos os agentes da transformação de uma educação formal. E esse embate me deixa muito triste, tem muita resistência (Grupo Focal - Professora P3 - 4으ano).

Muitas vezes quando a gente pede participação dos pais eles dizem que não tem tempo, como que dizendo nas entrelinhas "o que essa professora está inventando? O trabalho é dela de dar conteúdo", fica subliminar essa ideia (Planejamento cooperativo - Professora P3 - 4ㅇano).

Mas também tem resistência das crianças, porque elas estão acostumadas com uma formalidade, naquela coisa que tudo que é mais fácil é melhor, o comodismo, [...] a gente se depara com isso toda a hora. Mas por que acontece isso? Porque alguns [professores] fazem assim com eles. Aí a gente é visto como aquele que tá inventando coisa, que tá se achando (Grupo Focal - Professora P4 - 2o ano).

As dificuldades narradas versam, sobretudo, acerca do aspecto comportamental, cultural e pedagógico no âmbito escolar para o desenvolvimento dos docentes como sujeitos pesquisadores de suas práticas. Não foram mencionados fatores como falta de formação ou tempo para desenvolver as atividades de pesquisa, o que sugere um interesse pela temática e, inclusive, a tentativa em situações anteriores de modificar esta situação. Os apontamentos trazidos evidenciam a falta de uma cultura informacional nas escolas conforme o relato da Professora P3 no grupo focal, a resistência da família indicado no planejamento cooperativo desta mesma professora, e uma cultura de acomodação disseminada pela cultura escolar como afirma a professora P4. Estas passagens parecem ainda reforçar a transmissão de conteúdos e uma aprendizagem no sentido estrito (PIAGET, 2002), além da própria figura do professor stricto sensu (BECKER, 2012a), da concepção pedagógica diretiva e do modelo epistemológico empirista (BECKER, 2012).

Pensar na mudança de um paradigma empirista de trabalho com informação e conhecimento para um modelo de desenvolvimento pleno do letramento informacional nas escolas perpassa todos os envolvidos no processo: professores, funcionários e comunidade escolar. $O$ apoio deve ser mútuo e retroalimentado, reforçando a importância da construção de conhecimentos tanto dos estudantes como dos professores, de maneira que coletivamente se desenvolva uma cultura de informação e não de reprodução, como pode ser observado nos relatos.

(C) ETD-Educação Temática Digital $\quad$ Campinas, SP $\quad$ v.19 $\quad$ n.3 $\quad$ p.786-804 jul./set. 2017 [800] 


\section{CONSIDERAÇÕES FINAIS}

Partindo do olhar do professor na produção dos dados, almejou-se chegar a respostas que contribuíssem com reflexões (sem pretensões conclusivas) das questões levantadas no momento da construção do objeto de estudo. Assim, notou-se que referente a pesquisa para a formação de si, o principal ponto positivo foi a comunicação entre pares como prática frequente entre as professoras, permitindo a troca tanto de informações e experiências como também o comportamento proativo das docentes para solucionar suas necessidades informacionais. Outrossim, frisamos que a valorização dos momentos de formação em que estiveram envolvidas atividades de pesquisa, como no caso da participação das professoras no Programa Observatório Nacional da Educação, pareceu algo preponderante e positivamente significativo para as educadoras. Contudo, a fragilidade teórica decorrente da centralidade em aspectos práticos nos parece um ponto negativo, além da dificuldade de acesso a recursos informacionais e midiáticos nas escolas e a própria ausência de formação específica para o trabalho com pesquisa escolar e letramento informacional que emergiram como pontos negativos.

Nota-se que, ao serem levadas a pesquisar algo para sua formação, as fontes de informação mais citadas pelas docentes foram os relatos pessoais, advindos de canais de informação como colegas de profissão e blogs de outros professores. Esta informação nos sugere primeiramente a possibilidade da falta de tempo dentre suas funções para a exploração de informações apresentadas em outros meios e, talvez por consequência deste primeiro ponto, falta de conhecimento e disponibilidade de outras vias para aquisição de informações por meio da pesquisa e troca entre pares, como os possibilitados por eventos da área, sites institucionais, entre outros, o que por fim resulta em uma cultura escolar de troca de informações baseada em "erro e acerto". Cabe destacar que o efeito desta situação resulta na fragilidade teórica e conceitual decorrida da ausência de fidedignidade das informações, fontes e canais utilizados, debilitando um efetivo trabalho com informação e conhecimento no e para o âmbito escolar.

Sobre os critérios utilizados pelas professoras para a avaliação de materiais de informação na prática da pesquisa, notamos que estes se centram na facilidade de localização do material e possibilidade de aplicabilidade em suas turmas, o que demonstra assim pouco conhecimento, acesso e/ou disponibilidade de tempo para recursos informacionais que demandam maior dedicação quanto à análise de informações que tenham maior aprofundamento teórico, aplicações em contextos diferentes daqueles em que as docentes se encontram e acesso a materiais (C) ETD-Educação Temática Digital Campinas, SP $\quad$ v.19 $\quad$ n.3 $\quad$ p.786-804 jul./set. 2017 
pertinentes a suas atividades, mas não disponíveis no ambiente de trabalho. Vale então reiterar que, ao utilizar o critério da conveniência, o trabalho do docente perde qualidade formal e o próprio desenvolvimento do letramento informacional fica comprometido.

Já como dificuldades citadas, a cultura informacional da escola, a equipe diretiva, colegas e familiares dos estudantes mostraram-se como impedimentos do pleno desenvolvimento da atividade de pesquisa, o que indica a urgência do trabalho com informação, com o conhecimento e com aspectos relacionados ao letramento informacional no âmbito escolar, envolvendo todos agentes participantes de forma direta e indiretamente com as atividades docentes, o que possibilitaria um suporte a este trabalho. Em diversos fragmentos das falas das docentes, foi possível verificar que quando a escola, através da equipe diretiva e dos colegas, assim como dos responsáveis pelos discentes não apoiam o desenvolvimento de atividades de investigação e, assim, a atuação do professor como orientador da pesquisa mostra-se limitada e com resultados comprometidos.

A avaliação da pesquisa, enquanto processo, também se revelou centrado na aplicabilidade das buscas feitas pelas professoras. Este aspecto aponta para o pragmatismo com que a atividade possa estar sendo sintetizada em sua execução, no qual o processo do desenvolvimento da pesquisa parece estar centrado majoritariamente no resultado final, daí a presença da prática da busca e centralidade na localização de informações como atividades erroneamente consideradas como sinônimos para pesquisa.

Podemos finalizar indicando ainda, que o compartilhamento de informações mostrou-se como aspecto de destaque. A troca de informações entre pares e a participação no Programa Observatório Nacional da Educação pelas professoras tornou-se discurso frequentemente reproduzido em suas falas, apontando para a importância dos momentos de troca de informações entre colegas de profissão e a formação continuada de longo tempo, em que se torna possível a troca de experiências e reflexões acerca de feitos e correções dos procedimentos.

(C) ETD-Educação Temática Digital $\quad$ Campinas, SP $\quad$ v.19 $\quad$ n.3 $\quad$ p.786-804 jul./set. 2017 [802] 


\section{REFERÊNCIAS}

BARDIN, Laurence. Análise de conteúdo. São Paulo, SP: Ed. 70, 2011.

BECKER, Fernando. Educação e construção do conhecimento. 2. ed. rev. Porto Alegre, RS: Penso, 2012.

BECKER, Fernando. Ensino e pesquisa: qual a relação? In: ; MARQUES, Tania B. I. (Org.). Ser professor é ser pesquisador. 3. ed. Porto Alegre, RS: Mediação, 2012.

BECKER, Fernando. O que é construtivismo? Revista de Educação, Brasília, DF, v. 21, n. 83, p. 7-15, 1992.

COUTINHO, Clara P. et al. Investigação-acção: metodologia preferencial nas práticas educativas. Revista Psicologia, Educação e Cultura, v. 13, n. 2, p. 355- 379, 2009.

DICKEL, Adriana. Que sentido há em se falar em professor-pesquisador no contexto atual?: contribuições para o debate. In: GERALDI, Corinta Maria Grisolia; FIORENTINI, Dario; PEREIRA, Elisabete Monteiro de Aguiar. (Org.). Cartografias do trabalho docente: professor-pesquisador. Campinas, SP: Mercado das letras, 1998.

FREIRE, Paulo. Pedagogia da autonomia: saberes necessários à prática educativa. 35.ed. São Paulo, SP: Paz e Terra, 2007.

FRISON, Lourdes Maria Bragagnolo. Pesquisa como superação da aula copiada. In: MORAES, Roque; LIMA, Valderez Marina do Rosário (Org.). Pesquisa em sala de aula: tendências para a educação em novos tempos. 2. ed. Porto Alegre, RS: EDIPUCRS, 2004.

GASQUE, Kelley Cristine G. Dias. Letramento Informacional: pesquisa, reflexão e aprendizagem. [e-book]. Brasília, DF: UNB, 2012.

GASQUE, Kelley Cristine G. Dias. Arcabouço conceitual do letramento informacional. Ciência da Informação, v.39, n.3, p. 83-92, set./dez. 2010.

GASQUE, Kelley Cristine G. Dias; TESCAROLO, Ricardo. Desafios para implementar o letramento informacional na educação básica. Educação em Revista, Belo Horizonte, MG, v.26, n.1, p. 41-56, 2010.

KEBACH, Patricia Fernanda Carmem. O professor construtivista: um pesquisador em ação. In: BECKER, Fernando; MARQUES, Tania B. I. (Org.). Ser professor é ser

pesquisador. 3. ed. Porto Alegre, RS: Mediação, 2012.

LÉVY, Pierre. Cibercultura. São Paulo, SP: Ed. 34, 2003.

(C) ETD-Educação Temática Digital Campinas, SP $\quad$ v.19 $\quad$ n.3 $\quad$ p.786-804 jul./set. 2017 [803] 
LIBÂNEO, José Carlos; OLIVEIRA, João Ferreira; TOSCHI, Mirza Seabra. Educação Escolar: Políticas, Estrutura e Organização. 8. ed. São Paulo, SP: Cortez, 2009.

MORAES, Roque; GALIAZZI, Maria do Carmo; RAMOS, Maurivam G. Pesquisa em sala de aula: fundamentos e pressupostos. In: MORAES, Roque; LIMA, Valderez Marina do Rosário (Org.). Pesquisa em sala de aula: tendências para a educação em novos tempos. 2. ed. Porto Alegre, RS: EDIPUCRS, 2004.

PIAGET, Jean. Para onde vai a educação? 16. ed. Rio de Janeiro, RJ: José Olympio, 2002.

RAMOS, Maurivan Guntzel. In: MORAES, Roque; LIMA, Valderez Marina do Rosário (Org.). Pesquisa em sala de aula: tendências para a educação em novos tempos. 2. ed. Porto Alegre, RS: EDIPUCRS, 2004.

SILVA, João Alberto da. O sujeito psicológico e o tempo da aprendizagem. Cadernos de Educação. v. 32, p. 229-250, jan. /abr. 2009.

SILVA, João Alberto da. O professor pesquisador e a liberdade do pensamento. In: BECKER, Fernando; MARQUES, Tania B. I. (Org.). Ser professor é ser pesquisador. 3. ed. Porto Alegre, RS: Mediação, 2012.

SILVA, João Alberto da; MARINHO, Júlio Cesar; SILVA, Grasiele Ruiz. Planejamento cooperativo como método de investigação da sala de aula. Revista Eletrônica de Educação, v. 9, p. 120-135, 2015. 